$\infty$

0

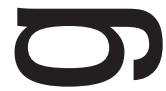

-

ת

1

$\longrightarrow$ 



\title{
OTIMIZAÇÃO DE MEDIDAS DE ENTROPIA DA PAISAGEM COMO SUBSÍDIO AO PLANEJAMENTO AMBIENTAL - REGIÃO DE GOIÂNIA - GO
}

\author{
OPTIMIZATION MEASURES OF ENTROPY LANDSCAPE GRANT AS THE ENVIRONMENTAL \\ PLANNING - REGION OF GOIÂNIA - GO \\ Elizon Dias Nunes - IESA/UFG \\ dn@geografia.grad.ufg.br \\ Patrícia de Araújo Romão - IESA/UFG \\ patricia1@iesa.ufg.br \\ Nilson Clementino Ferreira - CEFET-GO \\ ncferreira@uol.com.br
}

\section{Resumo}

Apresentam-se uma revisão do conceito de entropia, sua aplicação no estudo do relevo e uma rotina para cálculo com diferentes configurações de matriz e resolução espacial do Modelo Digital de Elevação (MDE) por meio de recursos de Geoprocessamento, com a finalidade de subsidiar o planejamento ambiental. A área de estudos envolve o município de Goiânia - GO. A metodologia consistiu na utilização de uma fórmula de cálculo de entropia, aplicada a uma matriz quadrada de convolução de $n \times n$ células do MDE relativo ao município de Goiânia. Nessa matriz de convolução, cada célula central foi classificada levando-se em conta a probabilidade de a mesma ocorrer na área analisada, por meio de funções de operações de vizinhança desenvolvidas no programa ArcGis 9.2, por meio de programação em SOL (Linguagem de Consulta Estruturada). Incluiu-se a elaboração e correlação das cartas de hipsometria, de declividade, de curvatura do perfil e plana das vertentes. Foi possível assim realizar o cálculo de entropia do relevo em diferentes configurações de matriz e em diferentes resoluções espaciais do $\mathrm{MDE}$, adequadas às feições do terreno, estando a ferramenta desenvolvida apta a ser utilizada no cálculo de entropia em outras áreas, utilizando para tanto um MDE. Ainda, a carta de entropia mostrou-se relevante na caracterização da diversidade altimétrica, possibilitando separar áreas com distintas classes de dissecação, o que auxiliou compreensão das formas do relevo da região de Goiânia.

Palavras-chave: entropia, paisagem, planejamento ambiental

\section{Abstract}

It presents a review of the concept of entropy, its application in the study of relief and a routine for calculating the matrix with different configurations and spatial resolution of the Digital Elevation Model through geoprocessing of resources in order to subsidize the environmental planning. The methodology was to use the formula for calculating the entropy applied to a square matrix of convolution of $n \times n$ cells of the DEM, in which a central cell was classified taking into account the likelihood that the same place in the surrounding area by DEM through the service of operations neighborhood developed in the program $\mathrm{Ar}$ cGIS 9.2 through programming in SOL (Structured Query of Language). It included the development and correlation of the letters of hypsometric, slope, curvature of the profile and the flat parts. It can perform the calculation of entropy of relief in different configurations and different array of spatial resolutions of the DEM at appropriate features of the terrain being, the tool developed, ready to be used in the calculation of entropy in other areas for using both curves level or a Digital Elevation Model. Although the letter of entropy was also relevant in the characterization of diversity altimetry, allowing separate areas with different classes of dissection auxiliary in understanding the ways of relief.

Key-words: entropy, landscape, environment planning

Boletim Goiano de Geografia $\quad$ Goiânia - Goiás - Brasil

v. 28

ก. 2

p. $125-140$

jul. / dez. 2008 



\section{Introdução}

O processo de apropriação do relevo pelo homem - seja como suporte ou recurso - responde pelo desencadeamento de reações que resultam no comportamento do modelado, considerando os efeitos morfodinâmicos convertidos em impactos (CASSETI, 2006). Assim, grande parte dos desequilíbrios, que se processam entre os componentes da paisagem natural, deve-se às intervenções humanas sem um prévio planejamento, ou seja, o uso do espaço sem levar em conta as suas limitações, com vistas a causar as menores interferências possíveis na dinâmica natural da paisagem.

A cidade, enquanto exemplo no qual a ação antrópica causa grandes modificações, constitui-se também em espaço onde se desencadeia grande parte dos problemas relacionados à degradação ambiental e que possuem sua gênese e evolução quando das intervenções humanas. Assim, a busca do conhecimento acerca dos aspectos da paisagem, bem como a sua provável dinâmica e comportamento, compreende um importante procedimento, por meio do qual é possível caracterizar o ambiente a ser ocupado, quanto às suas vulnerabilidades face às modificações impostas.

No que se refere ao planejamento do uso do espaço geográfico, a Geomorfologia assume grande importância. Tendo como objeto de estudo os processos de esculturação e as formas de relevo, ela vai de encontro direto aos maiores interesses do homem. Segundo Marques (1994, p. 25), esses interesses não são fortuitos, pois os relevos constituem os pisos sobre os quais se fixam as populações humanas no desenvolvimento das suas atividades, derivando daí valores econômicos e sociais que lhes são atribuídos.

No conhecimento geomorfológico encontra-se implícita a idéia de que o modelado terrestre evolui naturalmente como sendo resultado da influência exercida pelos processos morfogenéticos (CHRISTOFOLLETTI, 1979). Assim, as paisagens constituem respostas a um complexo de processos, cada um exigindo apropriadas escalas espaciais e temporais, para serem estudados. Tais processos devem-se às interações entre as forças endógenas - que se devem à energia advinda das porções mais internas da Terra - e as forças exógenas - representadas pela interação da energia do sol com os fluídos da atmosfera e hidrosfera (ZDENKOVIC; SCHEIDEGGER, 1989). Dessa forma, a paisagem é um sistema em equilíbrio dinâmico, que ao longo do tempo pode assumir distintas feições. Isso implica em afirmar que na dinâmica das paisagens não existe uma 
certeza quanto à forma que cada uma venha adquirir, pois no processo de esculturação do relevo há uma complexidade que se deve ao fluxo de matéria e à energia, bem como à estrutura na qual ocorrem inúmeras variáveis envolvidas na composição do sistema, havendo entre elas interação, interdependência e mecanismos de retroalimentação. O mecanismo de cada processo - descrito pela correlação entre as variáveis que o compõe - assim como por suas conseqüências, pode ser inferido de maneira probabilística (CRHISTOFOLETTI, 1979).

\section{Fundamentação teórico-metodológica}

No que concerne à caracterização do ambiente para uso e ocupação, tem-se utilizado nos últimos anos de várias metodologias para representação dos seus atributos físicos. Mapas hipsométricos e de declividades têm sido utilizados com sucesso na caracterização do relevo, melhorando assim o entendimento do mesmo. Esses parâmetros, se correlacionados, formam um arranjo espacial complexo e o seu entendimento enquanto sistema é evidenciado (Singh, 2000). Assim, alguns parâmetros do meio físico, como energia potencial, requerem análises mais sistêmicas, como a análise da distribuição altimétrica por unidade de área, associada às formas das vertentes - convexa, retilínea e côncava - para uma caracterização mais precisa dos processos que atuam no relevo. O movimento de matéria no relevo, no qual se inserem os processos erosivos, está diretamente associado à energia potencial disponível para realizar trabalho geomorfológico. A quantidade de energia depende preponderantemente da distribuição de altitudes em determinada área e caracterizam a entropia de uma paisagem. Ainda, o conceito de entropia, enquanto potencial de realizar trabalho geomorfológico se mostra de grande relevância para o emprego em regiões de clima tropical chuvoso, uma vez que nesses ambientes o forte intemperismo químico e físico, associado aos elevados índices pluviométricos - em especial chuvas intensas em áreas urbanas - e à dinâmica das águas fluviais, são os principais responsáveis pela dinâmica natural do relevo. Esses aspectos, somados à relativa estabilidade tectônica predominante na área, refletem em ambientes com elevada espessura do material inconsolidado e por isso, susceptíveis ao movimento de massa em ritmo acelerado quando das intervenções antrópicas. 
Dos impactos ambientais que se processam no município de Goiânia, o fenômeno dos processos erosivos continua sendo um dos que mais afetam a área urbana do município. Tal fenômeno foi abordado inicialmente por Santos (1997), que buscou verificar o comportamento de cada substrato rochoso sob influência da ação antrópica, na deflagração e aceleração de processos erosivos. Nascimento e Sales (2003) destacaram como principais causas dos processos erosivos, as galerias pluviais em áreas pavimentadas e a concentração de escoamento em áreas sem pavimentação. Romão (2006), em uma abordagem mais metodológica, ressalta as características morfométricas do relevo, ao associar as amplitudes altimétricas com os tamanhos dos interflúvios como indicação do potencial à perda de solos. Tais conclusões vieram acompanhadas do fato de que Goiânia, nos últimos trinta anos, tem passado por um forte processo de impermeabilização do solo, influenciado pela urbanização, com o lançamento concentrado das águas pluviais nos cursos d'água das microbacias que ocorrem no município.

\section{Entropia}

Originária de estudos da termodinâmica, o conceito de entropia foi descrito no início da década de 1850 foi introduzido na ciência em 1860 por Rudolf Clausius e se referia à razão entre a quantidade de calor trocado e a temperatura em um sistema. Entretanto, em 1824 em ensaio publicado, Nicolas Sadi Carnot já havia apresentado os conceitos de um ciclo térmico ideal, que se tornariam as bases da Segunda Lei da Termodinâmica. Esta implica em um sistema, que ao passar por algum processo em direção ao estado de equilíbrio, tende a aumentar sua entropia (MATTOS; VEIGA, 2002; Moreira et al, 2003; Passos, 2004). Por se inserir em uma temática mais abrangente - Teoria Geral dos Sistemas - (ZDENKOVIC; SCHEIDEGGER, 1989), suas aplicações se difundiram por diversas áreas do conhecimento.

\section{A entropia na termodinâmica}

O conceito de entropia foi definido estatisticamente por Boltzmann (1895), com o objetivo de caracterizar o estado de expansão de um gás ideal, cujas moléculas possuíam uma probabilidade $\boldsymbol{w}$ de serem encontradas em 
um compartimento $\boldsymbol{i}$ de um espaço-fase fechado (OREAR, 1983; Zdenkovic; Scheidegger, 1989), cuja função é apresentada (Eq. 1).

$$
S=K x \ln p \quad \text { Equação } 1 .
$$

Onde: $\boldsymbol{S}$ é a entropia; $\boldsymbol{K}$ é a constante de Boltzmann; $\boldsymbol{I n}$ é o logaritmo natural e $\boldsymbol{p}$ corresponde às diferentes probabilidades de estado em que o gás pode encontrar-se. Nesse sentido, as moléculas ao se expandirem estariam procurando um melhor arranjo, isto é, com o menor gasto de energia, que corresponde a uma maior probabilidade de o gás ser encontrado naquele determinado estado. Assim, o conceito de entropia foi introduzido para caracterizar o estado de ordem ou desordem em um sistema de partículas. Quanto maior for a probabilidade $\boldsymbol{p}$ de que o sistema esteja naquele estado particular, maior será o estado de desordem nas posições e velocidades de deslocamento das partículas nesse sistema, que devido a baixa energia disponível, levaria ao aumento de sua entropia.

\section{A entropia na teoria da informação}

Em relação à teoria da informação, o conceito de entropia foi introduzido em 1948 por Claude Shanonn, que propôs uma medida para quantificá-la (Eq. 2). Segundo aquele autor, uma fonte de informação é tida como um conjunto de elementos - signos - e está diretamente associada ao grau de similaridade entre as probabilidades de uma distribuição entre os mesmos. Estas probabilidades definem a entropia do conjunto, na medida em que os elementos aparecem com uma dada freqüência (Mattos; Veiga, 2002; Zdenkovic; Scheidegger, 1989).

$$
H=-\sum_{i=1}^{n} p_{i} \ln p_{i} \quad \text { Equação } 2 .
$$

Onde: $\boldsymbol{H}$ é a entropia calculada a partir do somatório dos produtos das diferentes probabilidades de ocorrência $\boldsymbol{p}$ dos valores de $\boldsymbol{i}$ variando de 1 a $n$, pelo seu respectivo logaritmo $\mathbf{I n}$. 


\section{Entropia da paisagem}

A aplicação da teoria da entropia no estudo das paisagens repousa sobre o conceito de energia enquanto capacidade de realizar trabalho geomorfológico, onde a distribuição da energia em uma paisagem pode ser representada como sendo a probabilidade de ocorrer determinada distribuição altimétrica do relevo em relação ao conjunto (CHRISTOFOLLETTI, 1979). Segundo esse mesmo autor, Luna B. Leopold e W. B. Langbein (1962) foram os primeiros a utilizar o conceito de entropia no estudo das paisagens como um todo, empregando analogias com a termodinâmica. Assim, a altitude no relevo - aqui representada por um modelo digital de elevação - é análoga à temperatura em um sistema termodinâmico, enquanto a massa corresponde à energia térmica disponível no mesmo sistema (Eq. 3).

$$
\boldsymbol{d} S=\boldsymbol{d} Q / \boldsymbol{t}<==\boldsymbol{d} \boldsymbol{S}=\boldsymbol{d} \boldsymbol{M} / \mathbf{h} \quad \text { Equação } 3
$$

Onde: $\boldsymbol{d} \boldsymbol{S}$ corresponde a variação de entropia para ambos os lados; $\boldsymbol{d} \boldsymbol{Q}$ é a quantidade de calor e $\boldsymbol{t}$ corresponde a temperatura no sistema termodinâmico; $\boldsymbol{d} \boldsymbol{M}$ é a quantidade de massa e $\boldsymbol{h}$ é a amplitude altimétrica no relevo. Assim, as partículas de água e de sedimentos localizadas em determinadas posições altimétricas são atraídas pela ação da gravidade - energia potencial - para posições de menor altitude na paisagem, passando gradativamente para a forma de energia cinética. Dessa forma, cada cota altimétrica possui uma determinada quantidade de energia em função da altimetria, da forma das vertentes e do comprimento das mesmas. Portanto, enquanto na termodinâmica a temperatura absoluta de um sistema isobárico corresponde ao estado de máxima entropia, na geomorfologia esse estado aconteceria quando do aplainamento por completo da paisagem, a mesma chegando ao seu nível de base de erosão. Ainda, as medidas de entropia da paisagem permitem a inferência de medidas de similaridade ou diversidade do relevo, tendo em vista a sua relação com a distribuição de freqüência de altitudes em determinada área. Por conseguinte, essas medidas auxiliam na delimitação de compartimentos morfológicos, por refletirem essa homogeneidade ou diversidade quanto às amplitudes altimétricas e conseqüentemente quanto às feições do relevo. 


\section{Objetivos}

O presente trabalho objetiva - através do conceito de entropia aplicado ao estudo da evolução da paisagem - contribuir com os estudos voltados ao planejamento ambiental. Possui também o objetivo de contribuir com o conhecimento das feições do relevo, em escala maior que a existente (1:40.000), da área urbana e de expansão urbana de Goiânia. A partir do objetivo principal, objetivos específicos consistem em: i) elaborar a carta de entropia do relevo representando o índice de dissecação da região por meio da adaptação do programa em linguagem computacional (LEGAL), criado por Romão (2006), para um algoritmo de fácil aplicação e implementação no ambiente SPRING 4.3.2 e ArcGis 9.2; ii) evidenciar - através da relação de uso com a perda de solo - como a ocupação inadequada pode contribuir para a aceleração ou mesmo deflagração de processos erosivos; iii) realizar mapeamento morfométrico das feições do relevo referentes às porções das vertentes ou setores das vertentes iv) remodelagem e espacialização da espessura do material inconsolidado, correlacionando-a com as curvaturas dos perfis e planas das vertentes, para caracterização da susceptibilidade do terreno a erosões.

\section{Materiais e métodos}

No presente trabalho seguiu-se o método de correlação, o qual permite estabelecer a interdependência existente entre os atributos de uma dada área. Para tanto, a elaboração dos documentos cartográficos referentes aos aspectos morfométricos da área foi viabilizada por meio de tecnologias computacionais, aplicadas ao processamento de dados espaciais georreferenciados (Geoprocessamento). Para tanto, utilizouse o Mapa Urbano Básico Digital de Goiânia - MUBDG versão 20 - adquirido junto à Companhia de Processamento de Dados de Goiânia COMDATA - contendo elementos da planimetria e altimetria. O cálculo de probabilidade de altitudes no Modelo Digital de Elevação - MDE - foi realizado por meio de operações de vizinhança desenvolvidas no programa ArcGis 9.2, em SQL, (Linguagem de Consulta Estruturada), em uma matriz de convolução de $n \times n$ células, do MDE, na qual a célula central foi classificada levando-se em conta a probabilidade de a mesma 
ocorrer em outros locais da área compreendida pelo MDE, por meio da fórmula da Eq. 4.

$$
p_{i}=n_{i} / N \quad \text { Equação } 4 .
$$

Onde: pi é a probabilidade de uma determinada célula de altitude $\mathbf{n i}$ ocorrer em uma matriz quadrada de convolução $\boldsymbol{N}$, de $n \times n$ células. Em seguida aplicou-se a fórmula de cálculo de entropia apresentada na Eq. 5.

$$
H=-\sum_{i=1}^{n} p_{i} \ln p_{i} \quad \text { Equação } 5 .
$$

Onde: $\boldsymbol{H}$ é a entropia calculada através do somatório dos produtos dos logaritmos naturais (ln) por suas respectivas probabilidades $\boldsymbol{p}$, das respectivas cotas altimétricas e $\boldsymbol{i}$, variando da menor (1) a maior altitude $(n)$, representa a variação altimétrica. $\mathrm{Na}$ área de estudo a altimetria variou de 659 a 1037 m. O cálculo começou com a utilização de uma matriz de 7 x 7 células, com resolução espacial de $5 \mathrm{~m}$, seguida por uma matriz $9 \times 9$, com a mesma resolução. Fez-se uma reamostragem do MDE para uma resolução espacial de $10 \mathrm{~m}$ e aplicaram-se as diferentes matrizes citadas acima, até chegar a uma matriz de convolução de 9 x 9 células, com resolução espacial de $25 \mathrm{~m}$, a qual se mostrou compatível com a dimensão predominante dos interflúvios. A espacialização da espessura do material inconsolidado foi realizada mediante a aquisição de dados de sondagens geotécnicas constantes nos boletins de sondagens, realizadas por empresas atuantes na área de estudos, os quais foram organizados em um banco de dados geográficos.

\section{Resultados e discussão}

Por meio da programação em linguagem SQL (Linguagem de Consulta Estruturada) utilizada pelo programa ArcGis 9.2, foi possível realizar o cálculo de entropia do relevo em diferentes configurações de matriz e em diferentes resoluções espaciais do MDE. Assim, a ferramenta desenvolvida, seguindo a teoria do cálculo de entropia encontra-se disponível no Laboratório de Processamento de Imagens e Geoproces- 
sameto (LAPIG) e no Laboratório de Informática do Instituto de Estudos Sócio-Ambientais da UFG. Dessa forma, essa ferramenta está apta a ser aplicada para o cálculo de entropia em outras áreas, utilizando para tanto um MDE.

Da elaboração do mapa de entropia, a partir de uma matriz 9x9, com resolução espacial de $5 \mathrm{~m}$, as classes de diversidade são delimitadas e homogeneizadas somente em áreas com dissecações que ocorrem com elevada freqüência, justificadas pelas operações de vizinhança no MDE com essa resolução. Evidenciou-se também que, quanto maior a matriz de convolução aplicada em um MDE, maior é a tendência de homogeneização do relevo em classes de diversidade altimétrica, evidenciando assim uma maior interdependência com o entorno. Dessa forma, para uma área a ser mapeada, faz-se necessário, inicialmente, definir o tamanho da matriz de convolução e a resolução espacial do MDE compatíveis com as feições do relevo, para que as mesmas possam ser representadas. Ainda, quanto à resolução do MDE, a mesma deve possuir resolução compatível com as feições do terreno para a elaboração de representação de qualquer atributo morfométrico do mesmo, evitando assim representações que nem se aproximam da realidade.

Da carta de entropia do relevo a partir de uma matriz 9x9, com resolução espacial de 25m (Fig. 01), conclui-se que as classes de maior diversidade altimétrica - baixa entropia - se refletiram nas porções nordeste e sudeste do município, nas quais predomina uma maior dissecação do relevo. Entretanto, no que se refere aos processos erosivos, grande parte dos mesmos se concentra somente na porção sudeste. Ressalta-se que essa parte do município já se encontra bastante urbanizada, e que as primeiras moradias foram construídas em áreas inadequadas, que abrangem cabeceiras de drenagens e rupturas de declives. Na porção nordeste, ainda não urbanizada, embora predomine na mesma, classes de entropia de baixa a média, não se constatam processos erosivos acelerados (erosão no tempo histórico). Com relação às classes de alta entropia, as mesmas se localizam, em sua maioria, na planície de inundação do rio Meia Ponte, em sua porção compreendida pelo município de Goiânia. São ambientes de baixa diversidade altimétrica e que na estação chuvosa sofrem eventuais inundações em alguns locais, como na confluência do ribeirão João Leite com o Anicuns. 


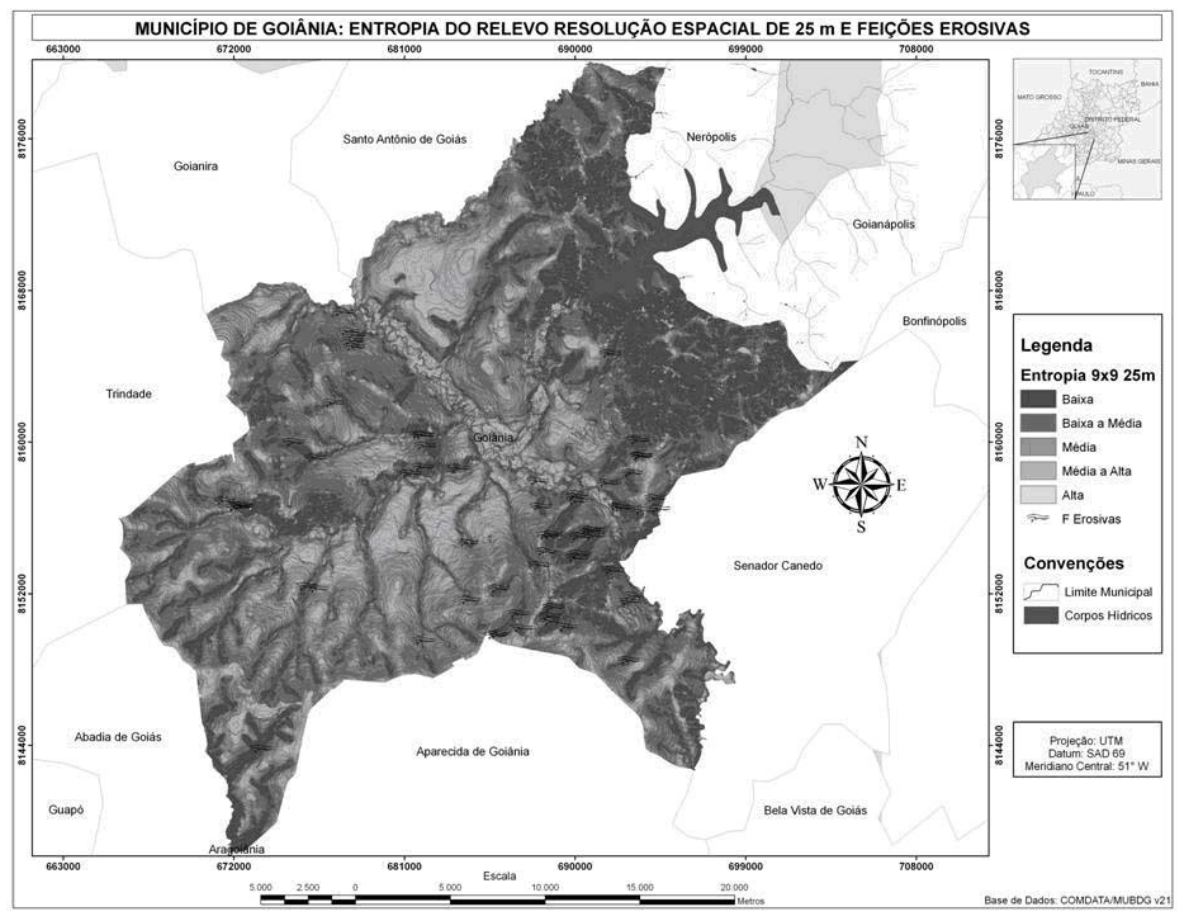

Fig. 01. Mapa de entropia do relevo, matriz 9x9, resolução de 25m e feições erosivas.

Correlacionando o mapa de entropia com o mapa de curvatura plana e do perfil das vertentes (Fig. 02), percebe-se que as classes de maior diversidade altimétrica correspondem espacialmente com os segmentos retilíneos e côncavos das vertentes. Isso explica, em grande parte a deflagração e evolução dos processos erosivos, para os quais, a velocidade e aceleração do fluxo de água dependem, além da diversidade altimétrica, das formas das vertentes. Assim, nos segmentos retilíneos e côncavos dessas, a energia potencializada por uma área de contribuição específica de um dado canal de drenagem, tende a convergir para uma área menor, que corresponde à cabeceira da drenagem. Dessa forma, pelo mesmo mapa de curvatura, percebe-se que grande parte das erosões localiza-se nas nascentes dos córregos, com curvatura plana côncava e curvatura do perfil também côncava, que indicam concentração de escoamento superficial quando das chuvas intensas de verão, comuns em áreas urbanas. Nos espaços que antecedem esses segmentos 
das vertentes, a curvatura plana côncava e do perfil convexo já indicam convergência lateral de fluxo.

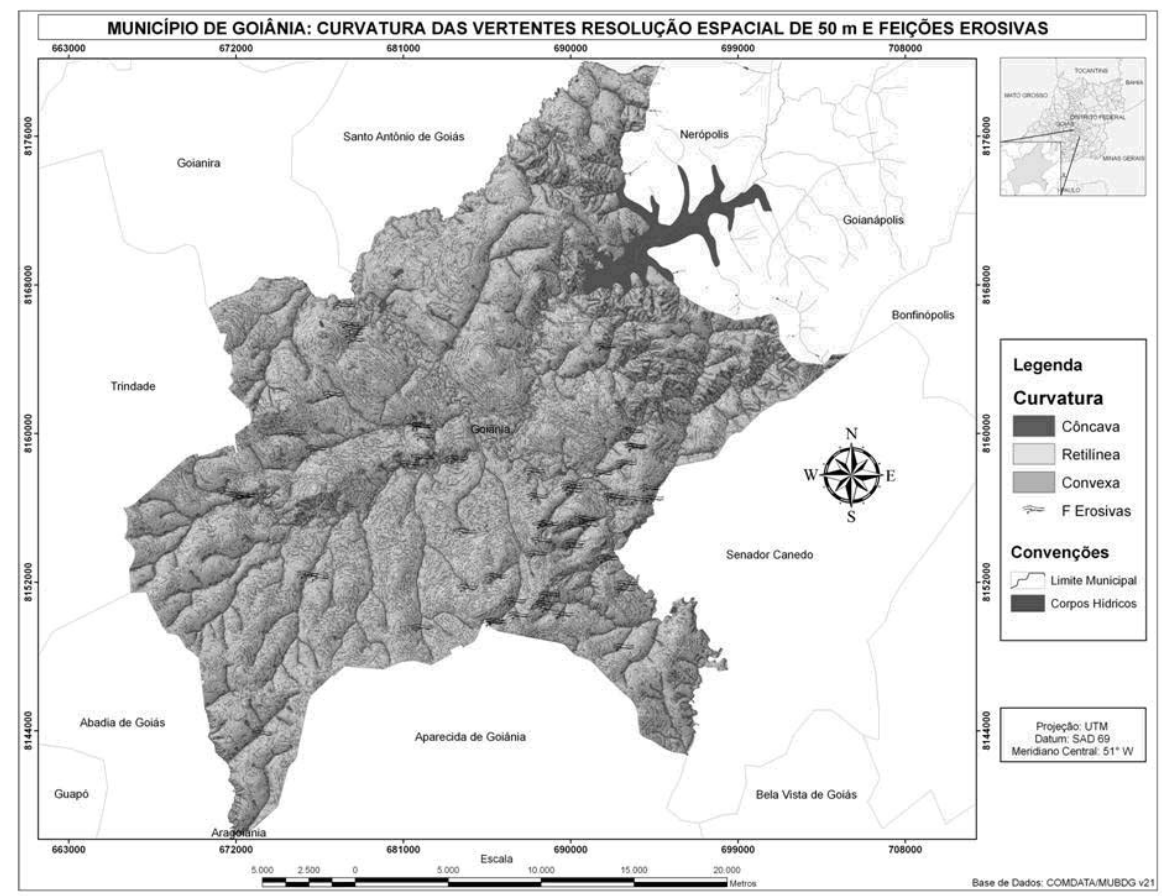

Fig. 02. Mapa de curvatura das vertentes, com resolução de $75 \mathrm{~m}$ e feições erosivas.

Os mapas anteriores, associados ao mapa de espessura do material inconsolidado (Fig. 03), confirmam uma maior tendência da deflagração e evolução de processos erosivos em ambientes, nos quais a referida espessura varia de 10 à $14 \mathrm{~m}$. São ambientes nos quais está a quase totalidade das nascentes dos córregos e que se localizam nos segmentos côncavos das vertentes. Por possuírem uma espessa camada de material alterado, associado à convergência de escoamento superficial, o mesmo se mostra susceptível à perda de solos. Assim, pela correlação dos mapas citados, observa-se que o entendimento do fenômeno dos processos erosivos necessariamente deve passar pela análise das múltiplas variáveis que caracterizam o relevo e também, em especial, pela forma de ocupação do mesmo. 


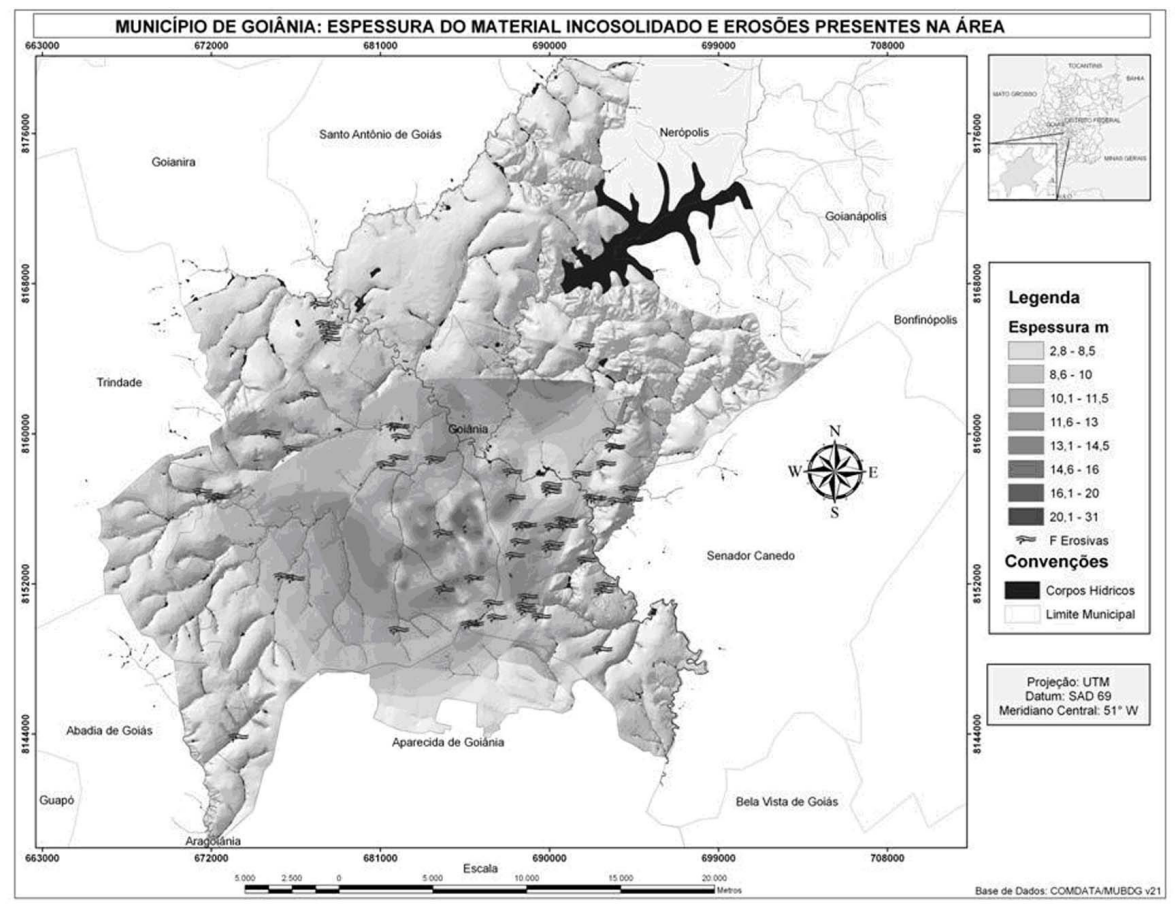

Fig. 03. Mapa da espessura do material inconsolidado de parte da área e feições erosivas.

\section{Considerações finais}

A análise do relevo por meio da carta de entropia mostrou-se relevante na caracterização da diversidade altimétrica. Considerando a resolução do Modelo Digital de Elevação e o tamanho da matriz empregada no mesmo, foi possível separar áreas com distintas classes de dissecação do relevo, auxiliando assim, na compreensão das formas do terreno. Com isso, o emprego de operações de vizinhança com diferentes matrizes quadradas e com diferentes resoluções espaciais de células do MDE, pode ser considerado como uma instrumentação tecnológica aplicada na caracterização do relevo para fins de planejamento, pois essa caracterização permite uma correlação com o potencial erosivo, presente em cada forma existente na área. Tal procedimento oferece possibilidade de emprego de várias configurações de matriz e resolução do MDE. Ainda, ao classificar uma célula central de uma determinada matriz de altimetria, levando-se em conta as altitudes das células 
adjacentes à mesma, é possível compreender o caráter de contigüidade e interdependência presente nas feições que o caracterizam, bem como se dá a distribuição da energia, enquanto capacidade de realizar trabalho geomorfológico. Com relação à predominância de classes de baixa e média entropia na porção nordeste do município, por causa da elevada diversidade altimétrica e não urbanização, conclui-se que a mesma deve receber atenção especial por parte dos órgãos de planejamento, evitando assim o desencadeamento de processos erosivos, como aconteceu na porção sudeste. Por conseguinte, os diversos mapas utilizados mostraram-se relevantes para uma análise mais sistêmica do relevo, contribuindo assim para o planejamento do ambiente.

\section{Referências}

CAMPOS, J. E. G; RODRIGUES, A. P; ALMEIDA, L; RESENDE, L; MAGALHÃES, L. F; MARANHÃO SÁ, M. A. Diagnóstico Hidrogeológico da Região de Goiânia. Goiânia, 125 p. 2003.

CASSETI, Valter. Geomorfologia do Município de Goiânia - GO. Boletim Goiano de Geografia, Goiânia, p. 65-85, 1993.

CHRISTOFOLETTI, Antônio. Geomorfologia. $2^{\circ}$ ed. São Paulo, Editora Edgard Blücher, 188p. 1980.

CHRISTOFOLETTI, Antônio. Modelagem de Sistemas Ambientais. São Paulo, Editora Edgard Blücher, 236p. 1999.

CHRISTOFOLETTI, A. L. H. Sistemas Dinâmicos: As Abordagens da Teoria do Caos e da Geometria Fractal em Geografia. In VITTE, A. C; GUERRA, A, J. T. (Org) Reflexóes Sobre a Geografia Física no Brasil. Rio de Janeiro, Editora Bertrand Brasil, 89 - 110, 2004.

IPLAN - Instituto de Planejamento Municipal. Plano de desenvolvimento Integrado de Goiânia, vol.1, IPLAN, Goiânia, GO, 112 p.1992.

MARQUES, J. S. Ciência Geomorfológica. In GUERRA, A, J, T; CUNHA, S, B da. (Org) Geomorfologia: Uma atualização de bases e conceitos. $7^{\circ}$ edição, São Paulo, Editora Bertrand Brasil, $23-45,1995$.

MATTOS, R. S; VEIGA, A. Otimização de entropia: Implementação Computacional dos Princípios Maxent e Minxent. Scielo Brazil, 2002. Disponível em < http://www.scielo.br/scielo.php ?script=sciarttext\&pid=S010174382002000100003 >Acesso em: 22 mar. 2007.

MOREIRA, C. V. R; FERREIRA, O. C; JUNIOR, P. P. M. Aplicação da Termodinâmica para a Avaliação do Equilíbrio das Redes Fluviais - a Bacia do Rio Santo Antônio. Economia e Energia, 2003. Disponível em: http://ecen.com/eee36/termodinamc.htm . Acesso em: 22 nov. 2007.

NASCIMENTO, M. A. S; PODESTÁ FILHO, A. Carta de risco de Goiânia. Boletim Goiano de Geografia, Goiânia, p. 95-105, 1993. 
OREAR, J. Fundamentos da Física 1. Rio de Janeiro. Editora MacGraw-Hill do Brasil. Tradução e Coordenação de Equipe Jaime Oltramari, 229 p. 1983.

PASSOS, J. C. Carnnot e a Segunda Lei da Termodinâmica. ABENGE, 2003. Disponível em< http://www.lepten.ufsc.br/publicaçoes/emperiódicos/2003/ABENGE/passos.pdf > . Acesso em: 19 Abr. 2008.

ROMÃO, P. A. Modelagem de Terreno com Base na Morfometria e em Sondagens Geotécnicas - Região de Goiânia - GO. 2006. 166 p. Tese (Doutorado em Geotecnia) - Faculdade de Tecnologia, Universidade de Brasília, Brasília 2006.

SANTOS, R. M. M. Caracterização Geotécnica e Análise do Processo Evolutivo das Erosões no Município de Goiânia. 1997. 120 p. Dissertação (Mestrado em Geotecnia) - Faculdade de Tecnologia, Universidade de Brasília, Brasília, 1997.

SCHEIDEGGER, E. A. A Complete thermodynamic analogy for landscape evolution. U.S. Geological Survey, University of Illinois, Illinois, U.S.A. Disponível em $:<$ http://www.cig.ensmp. fr/iahs/hsj/124/hysj_12_04_0057.pdf >. Acesso em: 10 mar. 2007.

SING, Vijay P. The entropy theory as a tool for modelling and decision-making in environmental and water resources. Water S A, South Africa, Vol. 26, N 1, Jan. 2000.

ZDENKOVIC, L. M.; SCHEIDEGGER, E. A. Entropy of landscapes. Zeitschrift Fur Geomorphology. N.F, Berlin-Stuttgart, p. 361-371, September, 1989.

Elizon Dias Nunes - Graduando em geografia pela Universidade Federal de Goiás

Patrícia de Araújo Romão - Professora do Instituto de Estudos Sócio-Ambientais da Universidade Federal de Goiás

Nilson Clementino Ferreira - Professor do Centro Federal Tecnológico de Goiás

Recebido em novembro de 2008 Aceito para publicação em dezembro de 2008 
